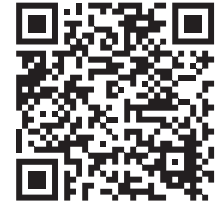

* Subdirector de Programas Extramuros del Instituto Nacional de Rehabilitación.

Correspondencia: JJBP, jjbustos@prodigy.net.mx Conflicto de intereses: Sin conflicto de intereses. Citar como: Bustos PJJ. Testimonio: primera queja en la CONAMED. Rev CONAMED. 2021; 26(4): 166-169. https://dx.doi. org/10.35366/102502

Financiamiento: No hubo financiamiento.

Recibido: 15/10/2021. Aceptado: 15/10/2021.

\section{Testimonio: primera queja en la CONAMED}

\author{
Testimony: first complaint at CONAMED \\ José Julio Bustos Pérez*
}

Buenos días a todos, muchas gracias por la invitación. Dr. Onofre Muñoz Hernández y Dr. Miguel Ángel Lezana Fernández: es muy agradable participar en este evento, ya que nos trae muy gratos recuerdos de cuando empezó esta importante institución.

Su inicio fue muy interesante, como comentaba el Dr. Héctor Fernández Varela, el día 05 de junio me indicó lo siguiente: «Manténgase atento para el día de mañana porque ya se dio a conocer la creación de la Comisión Nacional de Arbitraje Médico (CONAMED) y quizás pueden llegar una o dos personas que tengan quejas en su atención médica y preguntar de qué se trata».

Entonces llevamos a la sede de la CONAMED un escritorio, unas hojas en blanco, unos libros médicos y nuestras plumas; le solicité al Dr. Ramiro García Durán, también especialista con experiencia clínica, que me acompañara; apenas estaban habilitándose las oficinas en los pisos, de manera tal que fue en la recepción, subiendo las escaleras de la entrada, donde nos ubicamos. Para nuestra sorpresa llegó un grupo importante de personas que deseaban ser atendidos, y ahí compartiendo el escritorio se empezó la atención a los usuarios.

Me tocó la primera queja, que curiosamente no fue médica, sino de odontología, fue el expediente 001 , de la señora María Alicia (omitimos apellidos por confidencialidad), quién refirió en resumen que había tenido un problema en una clínica de IMSS por la extracción de un tercer molar, que el procedimiento fue muy complicado, tardando tres horas y con muchos «piquetes» de anestesia; posteriormente aún días después, no podía abrir la boca y tenía falta de sensibilidad en ese lado del rostro. En este caso, ella ya había presentado la queja en la Comisión de Derechos Humanos y la Coordinación de Atención y Orientación de Quejas del Seguro Social y no había obtenido resultados.

En la CONAMED, para mejor análisis del caso clínico, se pidió a la Asociación Dental del Distrito Federal que un cirujano maxilofacial y un odontólogo acreditados revisaran a la paciente y verificaran la situación y conjuntamente con el análisis del expediente clínico en la CONAMED. Se estableció que tenía una lesión del trigémino en su área mandibular, consecuencia del procedimiento con deficiencia en la atención otorgada, por lo que se solicitó al IMSS una indemnización que se otorgó a la paciente, que correspondía a los gastos que había realizado con odontólogos privados y del pago de un programa de rehabilitación mandibular. Con mejoría de la paciente, este proceso tardó aproximadamente tres meses y así fue resuelta la primera queja en la CONAMED.

Ese primer día de operaciones llegaron en total 37 pacientes, al escuchar a 17 de ellos y revisar los documentos que llevaban, se les explicó y demostró (con apoyo de 
los libros que llevamos) que no había realmente un error médico o una acción incorrecta, quedando satisfechos con nuestra atención, considerándose como asesorías. Los otros 20 casos fueron ingresados como queja para obtener más información de los pacientes, de los médicos y del expediente clínico para un análisis imparcial y búsqueda de resoluciones justas.

Por dar un ejemplo de la pauta en los casos de resolución inmediata, les comentaré un caso que llegó en los siguientes días, en el cual un señor llegó muy inquieto, ya que al visitar a su hermano operado de urgencia se dio cuenta de que tenía la herida abierta y se quejaba de que «los doctores ni siquiera se tomaron el tiempo de cerrarlo»; como cirujano especialista, le comenté que de acuerdo con los datos que llevaba, su hermano había sufrido una peritonitis grave y en esas situaciones se deja la herida con la piel abierta para evitar abscesos y el riesgo de una infección por anaerobios; al explicarle mostrándole gráficas e imágenes quedó satisfecho y con su inquietud resuelta. Ésta fue la tónica que ocurrió posteriormente porque esos casos eran resueltos sólo con asesoría e información, correspondiendo a 48\% de las solicitudes. Esas inquietudes empezaron a reflejar la principal causa de queja, que era la falta de comunicación de los médicos tratantes con los pacientes y sus familiares, ya que no explican o utilizan términos que la gente no entiende y por lo tanto, queda la información confusa; el otro 52\% de los casos se ingresaban como queja.

El primer día fueron 17 asesorías y 20 quejas, de ellas fueron nueve del IMSS, seis del ISSSTE y cinco privadas. Las quejas se atendían en el área de conciliación (que se estableció en los siguientes días), donde se analizaban con todo detenimiento las quejas por especialistas, se obtenía mayor información de médicos y pacientes y se buscaba la solución correcta.

Como comentó el Dr. Fernández Varela, se atendían las quejas de forma imparcial y por los especialistas correspondientes, por lo que se estableció todo un sistema contratando a médicos jubilados del IMSS que tenían experiencia en esa institución para atender los casos del IMSS, igualmente respecto al ISSSTE y otros con experiencia privada, que además estaban apoyados en los casos más complicados por asesores externos designados por la Academia Nacional de Medicina y la Academia Mexicana de Cirugía, que nos dieron una lista de asesores de cada especialidad.

Es así que aunque en la CONAMED teníamos en nuestro personal en el área de conciliación a tres cirujanos, un ginecoobstetra, un traumatólogo y un otorrinolaringólogo, también se contaba con el apoyo de los asesores externos.

En la Dirección General de Conciliación se analizaban las quejas a profundidad, escuchando al paciente y a sus familiares, se revisaban los documentos que tenían, se citaba al médico involucrado y se le pedía un informe médico, se solicitaba y estudiaba el expediente del paciente, se citaba a ambos, se establecía el diálogo entre ambos y se buscaba solucionar los casos imparcialmente, con satisfacción y resultados justos para pacientes y prestadores de servicio, cerrando con un acta de conciliación con los compromisos entre las partes. A los 20 días de abrir nuestras puertas se hizo la primera conciliación en un caso privado de pediatría.

Fue muy interesante el inicio de operaciones de la CONAMED, para tener buenos resultados el Dr. Fernández Varela estableció de inmediato un programa de trabajo con indicadores precisos de calidad, con logros como el de que un paciente que llegaba a las puertas de la CONAMED era atendido en un máximo de 15 minutos en el servicio de orientación y quejas, y las solicitudes que llegaban a la comisión, las asesorías quedaban resueltas de inmediato, y las quejas que pasaban a conciliación, desde que llegaba el usuario a las puertas de nuestra institución a quedar resueltas, si eran privadas se solucionaban en promedio en 20 días hábiles y las institucionales se solucionaban en 50 días hábiles.

Esos resultados se mantuvieron durante los primeros cuatro años en la administración en la que estuvimos con el Dr. Fernández Varela, con el trabajo intenso y comprometido de un personal en el que había médicos especialistas con experiencia clínica,junto con un grupo de apoyo de gente joven con mucho ímpetu, con un esquema de educación continua, ya que cada semana acudía un experto de alguna especialidad a dar conferencias a todo el personal para que se entendiera el acto médico, además de una reingeniería de procesos diaria, donde se evaluaba lo que ocurrió en el día y se analizaba cómo mejorar, con esa nueva propuesta 
acudíamos con el Dr. Fernández Varela, quien nos indicaba hacia dónde teníamos que ir para obtener mejores resultados y responder a los usuarios y a los prestadores de servicios médicos, con respeto, honestidad, imparcialidad y justicia.

El primer año se atendieron 4,025 casos y para el cuarto año se llegó a 12,000 casos, con 94\% resueltos (48\% por asesoría) y los que pasaron a conciliación, teníamos 91\% solucionados, 65\% mediante conciliación y $25 \%$ por otras modalidades. En $60 \%$ del total no se resolvían con dinero por indemnizaciones o reembolsos, a veces se lograba la reconciliación entre médicos y pacientes al establecer un diálogo entre ambos, con respeto y sin engaños, evitando el sistema estadounidense de demandas médicas por dinero, muchas veces el acuerdo se cerraba con una explicación, o al recobrar el paciente la confianza con una nueva atención médica. Eso para nosotros era satisfactorio, cuando volvían el médico y el paciente a tener esa relación, a platicar. Como ejemplo, un médico responsable decía: «discúlpeme, yo creo que hay algo que hice mal, permítame volver a atenderlo», y si estaba el paciente de acuerdo, con eso se solucionaba porque las personas recobraban la confianza en sus doctores, sólo 27\% se resolvía por reembolso, simplemente si alguien había cobrado la consulta en $\$ 500$ pesos, los regresaba porque no había sido una atención adecuada y sólo 9\% fueron por indemnización.

La capacidad de conciliación fue alta, ya que sólo 6\% pasaba al procedimiento de arbitraje médico. En el esquema de calidad de la CONAMED teníamos encuestas de salida con un nivel de satisfacción de 97\% de los pacientes y 95\% de los prestadores; de hecho el área de conciliación fue tercer lugar nacional en 1998 en el Concurso de Calidad de la SECODAM. Con esos resultados, Io que de inicio era muy difícil, obtener la confianza del gremio médico, se logró totalmente.

Otra importante actividad fue que al realizar estudios y detectar las causas de queja y de problemas médico-paciente, el Dr. Fernández Varela se dio a la tarea (en la que tuve oportunidad de acompañarlo) de ir a las academias, sociedades y grupos médicos en todo el país para prevenir que los errores encontrados siguieran ocurriendo, evitando que los casos médicos pasaran a juicios penales o civiles, sino que se atendieran en la CONAMED con concertación con las áreas jurisdiccionales, por lo que al mes de iniciar operaciones, nos tocó el primer dictamen pericial, se dio la opinión de la CONAMED y fue la que aceptó el ministerio público.

Creo también relevante comentarles que la primera actividad por oficio que atendió inmediatamente la CONAMED fue cuando hubo 11 defunciones de niños recién nacidos por infección en el antiguo Hospital Civil de Guadalajara. El Dr. Fernández Varela estableció un grupo de trabajo de expertos en infectología, pediatría, salud pública y personal de CONAMED que viajó a Jalisco, ahí al estudiar la situación con los médicos locales se encontró como causa infección intrahospitalaria por Enterobacter cloacae, y se determinó que efectivamente hubo fallas en el proceso de atención por contaminación, que fue parte de la causa de la muerte de esos niños. Por lo tanto, la CONAMED en agosto de 1996 elaboró la primera opinión técnica o recomendación dirigida al gobernador del estado de Jalisco, ya que era un hospital público, para que se cumplieran las normas para reducir los riesgos de infección intrahospitalaria y los cuidados de los comités de mortalidad y de infecciones. Posteriormente se volvió a visitar el lugar y se encontró que cumplieron con la recomendación, inclusive construyeron una nueva área de neonatología con filtros sanitarios, personal capacitado y el equipo necesario.

También se atendieron otros casos importantes de impacto nacional, como el de cinco muertes por un error en los tanques de gases en el Hospital General de Puerto Vallarta (se suministró dióxido de carbono $\left[\mathrm{CO}_{2}\right]$ en lugar de oxígeno $\left[\mathrm{O}_{2}\right]$ ) en el año 2000 , en ese caso también se elaboró una recomendación que permitió cambiar las normas de manejo de gases para que nunca volviera a ocurrir ese error, en el que la empresa de suministro de gases llevó un tanque de $\mathrm{CO}_{2}$ en vez de oxígeno.

Como comentó el Dr. Fernández Varela, otra actividad relevante fue el reconocimiento internacional, ya que funcionarios de salud de Colombia solicitaron un seminario de resolución de controversias médico-paciente, que impartieron directivos de la CONAMED encabezados por el comisionado en enero de 1997. Posteriormente también se dio en Perú, que en el año 2000 estableció su Centro de Conciliación y Arbitraje siguiendo los lineamientos establecidos en México. 
Por otra parte, en el proceso de buscar la mejoría de los servicios médicos en México, al Dr. Héctor Fernández Varela y a un servidor nos tocó ser fundadores de la Comisión Nacional de Certificación de Hospitales, y fue en la CONAMED donde se elaboraron los primeros criterios y estándares para la certificación. Y también se participó en Argentina representando a México junto con el Dr. Enrique Ruelas en el Congreso Internacional de Calidad de los Servicios Médicos.

Se trabajó intensamente con un gran líder, reconocido por muchas personas en el ámbito médico, junto a un grupo de trabajo de amigos que buscaban cumplir la misión de la CONAMED de contribuir a mejorar la calidad de los servicios en nuestro país.

Les agradezco mucho su atención. 